\title{
Predicting 6-Month Mortality in Incident Elderly Dialysis Patients: A Simple Prognostic Score
}

\author{
Josefina Santos ${ }^{a, b}$ Pedro Oliveira ${ }^{c, d}$ Jorge Malheiro ${ }^{a, b} \quad$ Andreia Campos $^{a}$ \\ Sofia Correia $^{a}$ António Cabrita $^{a}$ Luísa Lobato $^{a, b} \quad$ Isabel Fonseca ${ }^{a-c}$ \\ aDepartment of Nephrology, Hospital de Santo António, Centro Hospitalar do Porto, Porto, \\ Portugal; ${ }^{b}$ Unit for Multidisciplinary Research in Biomedicine, Instituto de Ciências Biomédicas \\ Abel Salazar Porto, Universidade do Porto, Porto, Portugal; ' $E P I$ Unit, ISPUP, Institute of \\ Public Health, Universidade do Porto, Porto, Portugal; ${ }^{d}$ Department of Population Studies, \\ Instituto de Ciências Biomédicas Abel Salazar Porto, Universidade do Porto, Porto, Portugal
}

\section{Keywords}

Elderly · End-stage renal disease · Dialysis - Prognosis score · Shared decision making

\begin{abstract}
Aim: Mortality in end-stage renal disease (ESRD) remains high, particularly among elderly, who represents the most rapidly growing segment of the ESRD population in wealthier countries. We developed and validated a risk score in elderly patients to predict 6-month mortality after dialysis initiation. Methods: We used data from a cohort of 421 patients, aged 65 years and over who started dialysis between 2009 and 2016, in our Nephrology department. The predictive score was developed using a multivariable logistic regression analysis. A bootstrapping technique was used for internal validation. Results: The overall mortality within 6 months was $14.0 \%$. Five independent predictors were identified, and a points system was constructed: age 75 years or older (2 points), coronary artery disease (2), cerebrovascular disease with hemiplegia (2), time of nephrology care before dialysis ( $<3.0$ months [2]; $\geq 3$ to $<12$ months [1]), and serum albumin levels (3.0-3.49 $\mathrm{g} / \mathrm{dL}[1] ;<3.0 \mathrm{~g} / \mathrm{dL}$ [2]). A score of 6 identified patients with a $70 \%$ risk of 6 -month mortality. Model performance was good in both discrimination (area under the curve of $0.793 ;[95 \% \mathrm{Cl} 0.73-0.86]$ ) and validation (concordance statistics of 0.791 [95\% $\mathrm{Cl} 0.73-0.85]$ ]). Conclusions: We developed a simple prediction score based on readily available clinical and laboratory data that can be a practical and useful tool to assess short-term prognosis in elderly patients starting dialysis. It may help to inform patients and their families about ESRD treatment options and provide a more patient-centered overall approach to care.




\section{Kidney \\ Blood Pressure \\ Research}

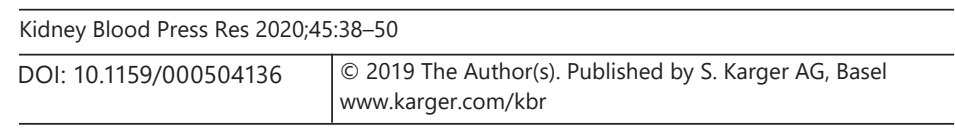

Santos et al.: Predicting 6-Month Mortality in Incident Elderly Dialysis Patients: A Simple Prognostic Score

\section{Introduction}

One of the challenges to clinicians caring for older chronic kidney disease (CKD) patients expected to progress to end-stage renal disease (ESRD) lies in the evaluation of the overall benefit of offering renal replacement therapy (RRT) to them. Although survival may have improved over time for older patients initiating dialysis [1], in those patients with high comorbidity, dialysis did not offer better survival compared to conservative management [2], with an overall decline in functional and cognitive status [3], and more hospitalizations [4].

For evaluating RRT benefits and risks and informing patients and their families about ESRD treatment options, there is a growing interest in developing predictive mortality models [5-10].

Portugal has the highest unadjusted incidence and prevalence of ESRD among European countries [11]. Although several scoring systems focused on older adults have been developed in other countries [7-10], they may be unsuitable for widespread application due to unproven generalizability.

We aimed to develop and validate a simple predictive risk score of early death after initiating dialysis using readily available variables to help the decision of initiating dialysis among elderly patients.

\section{Methods}

We conducted a retrospective cohort study of patients aged 65 years and over, referred to the Nephrology Department in Centro Hospitalar do Porto (CHP), who started dialysis as their first RRT, between January 2009 and December 2016. CHP is a tertiary-care hospital, which serves a diverse population of 500,000 inhabitants in the Northern region of the country.

The study was performed in accordance with the Declaration of Helsinki and approved by the Institutional Review Board of CHP.

Data were collected from medical records purposely for this study and included (at dialysis initiation): sex, age, weight, height, body mass index (BMI), medication, associated comorbid conditions, such as diabetes, dyslipidemia, hypertension, smoking status, history of malignancy, and cardiovascular disease (CVD). CVD included coronary artery disease, congestive heart failure (New York Heart Association stages I-IV), arrhythmia, peripheral artery disease, and cerebrovascular disease. Coronary artery disease was defined as a previous myocardial infarction, coronary artery bypass grafting, or coronary stent implantation. Peripheral artery disease was defined as the presence of intermittent claudication or with the need of peripheral revascularization or amputation. Cerebrovascular disease included both previous transient ischemic attacks and stroke, with or without hemiplegia.

Glomerular filtration rate (GFR) was estimated using the CKD Epidemiology 2009 creatinine equation [12]; all serum creatinine measurements were performed in the same laboratory calibrated using a calibrator for automated systems (Roche Diagnostics). Etiological diagnosis of CKD was based on the patient's history, kidney ultrasound, and kidney biopsy, when available.

Cognitive status was evaluated using the Mini Mental State Examination [13] with cognitive impairment defined for scores $\leq 23$. Functional dependency was defined as the requiring of assistance for transfer, classified as totally dependent or need assistance for transfer and autonomous.

A modified version of the Charlson comorbidity index (mCCI) [14], that is, by excluding subject's age and presence of kidney disease, was calculated and subdivided into 3 subgroups $(0-2,3-4, \geq 5)$. 


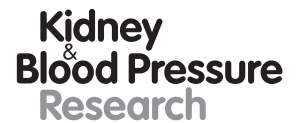

Research

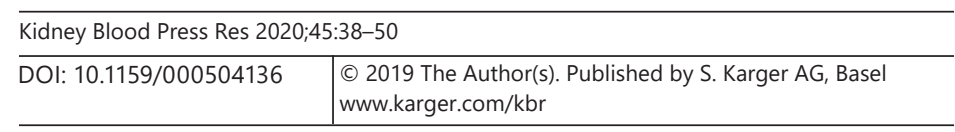

Santos et al.: Predicting 6-Month Mortality in Incident Elderly Dialysis Patients: A Simple Prognostic Score

Variables related to renal care included timing of nephrologist care prior to dialysis, dialysis modality, and vascular access (graft/fistula versus catheter) were collected. Timing of nephrologist care before dialysis was divided: under 3 months, between 3 and 12, and higher than 12 months. Late referral was defined as the first encounter with a nephrologist occurring within 3 months of the dialysis initiation. Unplanned dialysis was defined as any first treatment started for an emergency condition or not appropriate to delay for $>24 \mathrm{~h}$, even if a permanent dialysis access in place.

Since nephrology referral until RRT initiation, the number and reasons for hospitalizations were registered.

The study outcome was all-cause mortality within first 6 months following dialysis therapy initiation. Vital status was checked annually until August 30, 2017.

\section{Statistical Analysis}

Descriptive statistics on candidate predictors and the outcome variable are presented as median and interquartile range or percentage as appropriate.

Except for BMI (28 missing values), there was no missing among candidate predictors. Thus, no missing imputation approach was done in this study.

All $p$ values are two-tailed. A $p$ value $<0.05$ is considered to indicate statistical significance. Analyses were conducted with the use of the statistical package SPSS 24.0 (SPSS, Inc., Chicago, IL, USA) and STATA 13.0.

\section{Model Development}

Using 6-month mortality after dialysis initiation as the dichotomous outcome variable, several risk factors were first examined by univariable logistic regression: age (continuous or categorized as $\geq 75$ vs. $<75$ year), sex, BMI (continuous or categorized as $<25,25-30,>30$ $\mathrm{kg} / \mathrm{m}^{2}$ ), primary renal disease (diabetic nephropathy, autosomal dominant polycystic kidney disease, ischemic nephropathy, others and unknown vs. glomerulonephritis; diabetic nephropathy vs. other renal disease), smoking (current vs. former/never smoker), laboratory data (serum urea, serum creatinine, eGFR, and serum albumin), hypertension, diabetes mellitus, dyslipidemia, CVD history, chronic hepatic disease, chronic pulmonary disease, autoimmune disease, peptic ulcer, malignancy, mCCI, cognitive status (cognitive impairment/ dementia vs. normal), dependency for transfer (totally dependent, need assistance vs. autonomous), institutionalized (yes vs. no), hospitalizations on 6 months prior to dialysis initiation (number and categorized as yes and no), and referral time (under 3 months, between 3 and 12 , and higher than 12 months). Infection by hepatitis B, hepatitis C, and HIV was not tested due to small number of cases.

Variables that had an association with the outcome measure with a $p$ value $<0.2$ were selected for multivariable analysis. Continuous predictor variables were categorized as appropriate for simplicity in clinical use and to allow assignment of integer points, namely, age, eGFR, BMI, serum albumin, and referral time. Multivariable models were then built using backward selection $[15,16]$. Multicollinearity was checked using the variance influence factor.

\section{Risk Scoring System}

Considering the number of outcomes $(n=60)$ and the number of candidate predictors, the $\beta$-coefficients derived from final multivariable model were multiplied by a heuristic shrinkage factor to adjusting for overfitting [17-19]. The shrunken $\beta$-coefficients of the predictors in the final model were then divided by two-fifths of the 2 small $\beta$-coefficients in the model and rounded up to the nearest integer to give a simple point score [17]. 


\section{Kidney \\ Blood Pressure \\ Research}

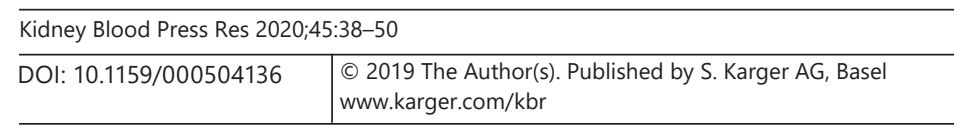

Santos et al.: Predicting 6-Month Mortality in Incident Elderly Dialysis Patients: A Simple Prognostic Score

\section{Model Validation}

The discrimination of the risk score was evaluated using the area under the receiveroperating characteristic curve (AUC). Due to the relatively small size of our cohort, we did not divide the cohort into derivation and validation samples. A bootstrapping procedure was used to internally validate the risk score and determine optimism $[8,18,19]$.

\section{Risk Scores Comparison}

The developed risk score in our work and Couchoud score [7] were calculated for each patient in order to determine the performance of each scoring system in predicting mortality. The discrimination of each scoring system was assessed and compared using AUC.

\section{Results}

\section{Patient Characteristics at Baseline}

Our study cohort included 421 individuals aged 65 years or older who started dialysis, during the study period. Table 1 shows their baseline characteristics, stratified by mortality status at 6 months after initiating dialysis. Their mean age was $75.5 \pm 6.3$ years, 195 patients $(46 \%)$ were female, about $50 \%$ were diabetic, and $97 \%$ of patients had eGFR of $<15 \mathrm{~mL} /$ $\mathrm{min} / 1.73 \mathrm{~m}^{2}$ at time of dialysis initiation. Most participants (98\%) were on hemodialysis. About $34 \%$ of participants had been hospitalized in the 6 months prior to dialysis initiation. More than half of our patients that started dialysis in life-threatening circumstances $(n=140$; $56 \%$ ) were timely referred to a nephrologist ( $\geq 12$ months).

\section{Predictors of 6-Month Mortality}

A total of 60 patients (14\%) died within 6 months of starting dialysis. Table 2 shows the results of univariable logistic regression analyses associated with mortality within 6 months after starting dialysis. Briefly, patients who died were more likely to be older and female and to have experienced any of the following conditions: an unplanned dialysis, being late referral, higher eGFR, lower albumin, need of assistance for transfer, cognitive impairment, to have been institutionalized, to have coronary artery disease, congestive heart failure, arrhythmia, cerebrovascular disease with hemiplegia, and higher mCCI. They were also more likely to have a hospital stay in the 6 months preceding dialysis initiation.

Multivariable logistic regression analyses with backward elimination procedure showed that the following variables were retained in the final model: age, coronary artery disease, cerebrovascular disease with hemiplegia, serum albumin level, and referral time (Table 3). Among the 16 candidate predictors (Table 2), unplanned dialysis was not included in the multivariable analysis, because we considered that the final model intended to be a tool also for those patients for whom the dialysis was not scheduled. The remaining 15 variables were divided in 3 sets of 5 candidate predictors, and backward elimination was applied separately to each set. Predictors that were selected in all of the 3 data sets were chosen as the final set of selected predictors. In each set of 5 variables, multicollinearity was checked, as well as the 10 variables included in the final model. The variance inflating factors were all near 1 (the maximum variance influence factor was 1.519).

Based on the number of 6 -month deaths $(n=60)$, the combination of 5 predictors was considered reasonably fitted to the final multivariable regression model. A Hosmer and Lemeshow goodness-of-fit test was not statistically significant, indicating good calibration of the model $\left(\chi^{2}, 7\right.$ degrees of freedom $=5.624 ; p=0.584$; Table 3$)$. 
Table 1. Demographic and clinical characteristics of study cohort

\begin{tabular}{|c|c|c|c|}
\hline & $\begin{array}{l}\text { Overall } \\
(n=421)\end{array}$ & $\begin{array}{l}\text { Died within } \\
6 \text { months }(n=60)\end{array}$ & $\begin{array}{l}\text { Did not die within } 6 \\
\text { months }(n=361)\end{array}$ \\
\hline Age, years & $75.5(70-80)$ & $77.9(73-84)$ & $75.1(70-80)$ \\
\hline Age $\geq 75$ years & 217 (51.5) & $42(70.0)$ & $175(48.5)$ \\
\hline Gender, female & 195 (46.3) & $33(55.0)$ & $162(44.9)$ \\
\hline \multicolumn{4}{|l|}{ Primary renal disease } \\
\hline Diabetic nephropathy & $156(37.1)$ & $24(40.0)$ & $132(36.6)$ \\
\hline Ischemic nephropathy & $69(16.4)$ & $10(16.7)$ & $59(16.3)$ \\
\hline Glomerulonephritis & 50 (11.9) & $4(6.7)$ & $46(12.7)$ \\
\hline ADPKD & $21(5.0)$ & $1(1.7)$ & $30(5.5)$ \\
\hline Other & $73(17.3)$ & $16(26.7)$ & $57(15.8)$ \\
\hline Unknown etiology & $52(12.4)$ & $5(8.3)$ & $47(13.0)$ \\
\hline $\mathrm{BMI}, \mathrm{kg} / \mathrm{m}^{2}$ & $26(23-29)$ & $28(22-28)$ & $26(24-29)$ \\
\hline$<25$ & $170(40.4)$ & $27(45)$ & $143(39.6)$ \\
\hline $25-30$ & $148(35.2)$ & $22(36.7)$ & $126(34.9)$ \\
\hline$>30$ & 75 (17.8) & $8(13.3)$ & $67(18.6)$ \\
\hline Cognitive impairment & $63(15.0)$ & $16(26.7)$ & $47(13.0)$ \\
\hline Totally dependent for transfer & $37(8.8)$ & $12(20.0)$ & $25(6.9)$ \\
\hline Need assistance for transfer & $188(44.7)$ & $32(53.3)$ & $156(43.2)$ \\
\hline Autonomous & $196(46.6)$ & $16(26.7)$ & $180(49.9)$ \\
\hline Institutionalization & $22(5.2)$ & 7 (11.7) & $15(4.2)$ \\
\hline mCCI & $3.8(2-5)$ & $4.7(3-7)$ & $3.7(2-5)$ \\
\hline $0-2$ & $127(30.1)$ & $11(18.3)$ & $116(32.1)$ \\
\hline $3-4$ & $130(30.9)$ & $17(28.3)$ & $113(31.3)$ \\
\hline$\geq 5$ & $164(39.0)$ & $32(53.3)$ & $132(36.6)$ \\
\hline Current/former smoking & $96(22.8)$ & $13(21.7)$ & $83(23.3)$ \\
\hline Diabetes & $212(50.4)$ & $32(53.3)$ & $180(49.9)$ \\
\hline Hypertension & 409 (97.1) & $58(96.7)$ & $351(97.2)$ \\
\hline Dyslipidemia & 375 (89.1) & $52(86.7)$ & $323(89.5)$ \\
\hline Congestive heart failure & $262(62.2)$ & $45(75.0)$ & $217(60.1)$ \\
\hline Coronary artery disease & $126(29.9)$ & $25(41.7)$ & $101(28.0)$ \\
\hline Cardiac arrhythmia & $101(24.0)$ & $20(33.3)$ & $81(22.4)$ \\
\hline Cerebrovascular disease & $137(32.5)$ & $20(33.3)$ & $117(32.4)$ \\
\hline With hemiplegia & $43(10.2)$ & $10(16.7)$ & $33(9.1)$ \\
\hline Peripheral vascular disease & $165(39.2)$ & $25(41.7)$ & $140(38.8)$ \\
\hline Neoplasia & $64(15.2)$ & $10(16.7)$ & $54(15.0)$ \\
\hline COPD & $74(17.6)$ & $14(23.3)$ & $60(16.6)$ \\
\hline Chronic liver disease & $30(7.1)$ & $5(8.3)$ & $25(6.9)$ \\
\hline Autoimmune disease & $16(3.8)$ & $1(1.7)$ & $15(4.2)$ \\
\hline Peptic ulcer & $62(14.7)$ & $8(13.3)$ & $54(14.9)$ \\
\hline Albumin $<3.5 \mathrm{~g} / \mathrm{dL}$ & $3.6(3.2-4.0)$ & $3.1(2.8-3.5)$ & $3.6(3.3-4.0)$ \\
\hline$\geq 3.5$ & $255(60.6)$ & $19(31.7)$ & $236(65.4)$ \\
\hline $3.0-3.49$ & $87(20.7)$ & $15(25.0)$ & $72(19.9)$ \\
\hline$<3.0$ & 79 (18.8) & $26(43.3)$ & $53(14.7)$ \\
\hline Creatinine, mg/dL & $6.3(4.7-7.5)$ & $6.1(4.3-7.4)$ & $6.3(4.9-7.5)$ \\
\hline eGFR EPI, mL/min/1.73 m² & $7(5-8)$ & $8(5-9)$ & $7(5-8)$ \\
\hline$\geq 15$ & $12(2.9)$ & $5(8.3)$ & $7(1.9)$ \\
\hline $10-14.9$ & $43(10.2)$ & $4(6.7)$ & $39(10.8)$ \\
\hline$<10$ & $366(86.9)$ & $51(85.0)$ & $315(87.3)$ \\
\hline \multicolumn{4}{|l|}{ Time of nephrology care before dialysis, months } \\
\hline$<3$ & 83 (19.7) & $28(46.7)$ & $55(15.2)$ \\
\hline$\geq 3$ to $<12$ & $43(10.2)$ & $7(11.7)$ & $36(10.0)$ \\
\hline$\geq 12$ & $295(70.1)$ & $25(41.7)$ & $270(74.8)$ \\
\hline Dialysis modality: hemodialysis & $411(97.6)$ & $60(100.0)$ & $351(97.2)$ \\
\hline Unplanned dialysis & $249(59.1)$ & $53(88.3)$ & $196(54.3)$ \\
\hline Access at first dialysis: catheter & $181(42.9)$ & $47(78.3)$ & $134(37.1)$ \\
\hline Hospitalizations 6-months before dialysis & $144(34.2)$ & $24(40.0)$ & $120(33.2)$ \\
\hline Hospitalizations per patient & $0.46(0.00-1.00)$ & $0.72(0.00-1.00)$ & $0.41(0.00-1.00)$ \\
\hline
\end{tabular}

Data expressed as medians and interquartile ranges (IQR) or $n(\%)$ when appropriate.

BMI, body mass index; mCCI, modified Charlson Comorbidity Index; COPD, chronic obstructive pulmonary disease; eGFR, estimated glomerular filtration rate using the chronic kidney disease epidemiology; $n$ hospitalizations, number of hospitalizations based on 6 months prior to dialysis initiation. 
Table 2. Results of the univariable logistic regression for 6-month mortality

\begin{tabular}{|c|c|c|c|}
\hline & OR & $95 \% \mathrm{CI}$ & $p$ value \\
\hline Age (per 1-year older) & 1.07 & $1.03-1.12$ & 0.002 \\
\hline Age category ( $\geq 75$ vs. $<75$ years) & 2.48 & $1.37-4.47$ & 0.030 \\
\hline Gender, female vs. male & 1.50 & $0.87-2.60$ & 0.147 \\
\hline \multicolumn{4}{|l|}{ Primary renal disease (ref. glomerulonephritis) } \\
\hline Diabetic nephropathy & 2.09 & $0.69-6.35$ & 0.193 \\
\hline Ischemic nephropaty & 0.56 & $0.06-5.47$ & 0.630 \\
\hline ADPKD & 1.95 & $0.57-6.62$ & 0.284 \\
\hline Others & 3.23 & $0.02-1.43$ & 0.048 \\
\hline Unknown etiology & 1.22 & $0.31-4.84$ & 0.774 \\
\hline Cognitive status (impairment/dementia vs. normal) & 2.43 & $1.27-4.65$ & 0.007 \\
\hline \multicolumn{4}{|l|}{ Functional dependency (ref. autonomous) } \\
\hline Totally dependent for transfer & 5.40 & $2.3-12.7$ & $<0.001$ \\
\hline Need assistance for transfer & 2.31 & $1.22-4.37$ & 0.010 \\
\hline Institutionalization (yes vs. no) & 3.05 & $1.19-7.82$ & 0.021 \\
\hline mCCI score (per 1 unit greater) & 1.23 & $1.08-1.39$ & 0.002 \\
\hline \multicolumn{4}{|l|}{ m CCI score category (ref. 0-2) } \\
\hline $3-4$ & 1.59 & $0.71-3.54$ & 0.259 \\
\hline$\geq 5$ & 2.56 & $1.23-5.30$ & 0.012 \\
\hline Congestive heart failure (yes vs. no) & 1.99 & $1.07-3.71$ & 0.030 \\
\hline Coronary artery disease (yes vs. no) & 1.84 & $1.05-3.23$ & 0.034 \\
\hline Cardiac arrhythmia (yes vs. no) & 1.73 & $0.96-3.12$ & 0.070 \\
\hline Cerebrovascular disease with hemiplegia & 1.99 & $0.92-4.28$ & 0.079 \\
\hline Albumin (per $1 \mathrm{~g} / \mathrm{dL}$ greater) & 0.30 & $0.19-0.47$ & $<0.001$ \\
\hline \multicolumn{4}{|l|}{ Albumin category (ref. $\geq 3.5 \mathrm{~g} / \mathrm{dL}$ ) } \\
\hline $3.0-3.49 \mathrm{~g} / \mathrm{dL}$ & 2.59 & $1.25-5.35$ & 0.010 \\
\hline$<3.0 \mathrm{~g} / \mathrm{dL}$ & 6.09 & $3.14-11.8$ & $<0.001$ \\
\hline eGFR-EPI (per 1 mL/min/1.73 m² greater) & 1.09 & $1.00-1.18$ & 0.047 \\
\hline \multicolumn{4}{|l|}{ eGFR-EPI category (ref. $\geq 15 \mathrm{~mL} / \mathrm{min} / 1.73 \mathrm{~m}^{2}$ ) } \\
\hline $10-14.9 \mathrm{~mL} / \mathrm{min} / 1.73 \mathrm{~m}^{2}$ & 0.14 & $0.03-0.67$ & 0.014 \\
\hline$<10 \mathrm{~mL} / \mathrm{min} / 1.73 \mathrm{~m}^{2}$ & 0.23 & $0.07-0.74$ & 0.014 \\
\hline \multicolumn{4}{|l|}{ Time of nephrology care before dialysis (ref. $\geq 12$ months) } \\
\hline$<3$ & 5.49 & $2.98-10.14$ & $<0.001$ \\
\hline$\geq 3$ to $<12$ & 2.10 & $0.85-5.20$ & 0.109 \\
\hline Unplanned dialysis ${ }^{\ddagger}$ & 6.4 & $2.8-14.4$ & $<0.001$ \\
\hline \multicolumn{4}{|l|}{ Hospitalizations in 6 months before dialysis } \\
\hline (per 1 hospitalization greater) & 1.80 & $1.35-2.39$ & $<0.001$ \\
\hline Hospitalizations in 6 months before dialysis (yes vs. no) & 4.01 & $1.77-9.08$ & 0.002 \\
\hline
\end{tabular}

‡ Unplanned dialysis was not included in the multivariable model, as explained in Discussion section.

This table includes only the variables that showed a univariable association $(p<0.20)$ with 6 -month mortality and then selected for multivariable logistic model.

mCCI, modified Charlson Comorbidiy Index; eGFR EPI, estimated glomerular filtration rate using the chronic kidney disease epidemiology equation; ADPKD, autosomal dominant polycystic kidney disease.

\section{Derivation and Internal Validation of Risk Score}

The risk score derived is displayed in Table 4, ranging 0-10 points. The score was calculated for each patient of our study sample (median risk score $=2$ ). The distribution of patients and mortality according to score is presented in Table 5 . As an example, a score of 5 identified patients with a $50 \%$ risk of 6-month mortality (Fig. 1).

A risk assessment questionnaire for clinicians and patients' use is shown in Figure 2, exposing a simple method for establishing a patient's risk for the outcome depending on an individual's status for the 5 variables included in the tool. 
Table 3. Multivariable logistic regression model for 6-month mortality

\begin{tabular}{|c|c|c|c|c|}
\hline & $\begin{array}{l}\text { Regression } \\
\text { Coefficient }\end{array}$ & $\begin{array}{l}\text { Adjusted } \\
\text { OR }\end{array}$ & $95 \% \mathrm{CI}$ & $p$ value \\
\hline Age category ( $\geq 75$ vs. $<75$ years) & 0.97 & 2.63 & $1.38-5.02$ & 0.003 \\
\hline Coronary artery disease (yes vs. no) & 0.93 & 2.54 & $1.35-4.79$ & 0.004 \\
\hline \multicolumn{5}{|c|}{ Cerebrovascular disease with hemiplegia } \\
\hline (yes vs. no) & 0.95 & 2.58 & $1.07-6.21$ & 0.035 \\
\hline \multicolumn{5}{|l|}{ Albumin category (ref. $\geq 3.5 \mathrm{~g} / \mathrm{dL}$ ) } \\
\hline $3.0-3.49 \mathrm{~g} / \mathrm{dL}$ & 0.85 & 2.35 & $1.09-5.05$ & 0.029 \\
\hline$<3.0 \mathrm{~g} / \mathrm{dL}$ & 1.46 & 4.31 & $2.07-8.97$ & $<0.001$ \\
\hline \multicolumn{5}{|c|}{ Time of nephrology care before dialysis (ref. $\geq 12$ months) } \\
\hline$<3.0$ months & 1.41 & 4.09 & $2.06-8.12$ & $<0.001$ \\
\hline$\geq 3$ to $<12$ months & 0.63 & 1.88 & $0.72-4.90$ & 0.199 \\
\hline Intercept & -3.91 & 0.18 & & \\
\hline \multicolumn{5}{|l|}{ C-statistic: 0.793} \\
\hline Hosmer-Lemeshow test: $p=0.584$ & & & & \\
\hline
\end{tabular}

Variables were retained in the model using backward elimination (Wald) procedure.

Table 4. Predictors of 6-month mortality and associated risk scoring system

\begin{tabular}{lll}
\hline & $\begin{array}{l}\text { Shrunken } \beta \text {-regression } \\
\text { coefficient }^{\ddagger}\end{array}$ & Risk score $^{\S}$ \\
\hline $\begin{array}{l}\text { Age category ( } \geq 75 \text { vs. }<75 \text { years) } \\
\text { Coronary artery disease (yes vs. no) }\end{array}$ & 0.86 & 2 \\
$\begin{array}{l}\text { Cerebrovascular disease with hemiplegia (yes vs. no) } \\
\text { Albumin category (ref. } \geq 3.5 \text { g/dL) }\end{array}$ & 0.83 & 2 \\
$\quad 3.0-3.49$ g/dL & 0.84 & 2 \\
$\quad<3.0$ g/dL & 1.30 & 2 \\
$\begin{array}{l}\text { Time of nephrology care before dialysis (ref. } \geq 12 \text { months) } \\
\quad<3.0 \text { months }\end{array}$ & 1.26 & 2 \\
$\quad \geq 3$ to $<12$ months & 0.56 & 1 \\
\hline
\end{tabular}

‡ Original $\beta$-regression coefficient multiplied by heuristic shrinkage factor.

$\S$ Scores assigned by dividing the shrunken $\beta$-regression coefficients by 0.528 (two-fifths of the 2 small $\beta$-coefficients in the model) and rounded to nearest integer.

Table 5. Distribution of patients and mortality according to score

\begin{tabular}{llllllll}
\hline Score & 0 & 1 & 2 & 3 & 4 & 5 & 6 \\
\hline Patients, $n(\%)$ & $61(14.5)$ & $121(28.7)$ & $112(26.6)$ & $52(12.4)$ & $43(10.2)$ & $25(5.9)$ & $7(1.7)$ \\
Deaths, $n(\%)$ & $2(3.3)$ & $4(6.7)$ & $13(21.7)$ & $8(13.3)$ & $16(26.7)$ & $13(21.7)$ & $4(6.7)$ \\
\hline
\end{tabular}

The predictive discrimination of 6-month mortality was good, with an AUC of 0.793 (95\% CI 0.73-0.86). A bootstrapping procedure was performed (5,000 bootstrap samples) to internally validate the risk score, which generated a concordance statistics of 0.791 (95\% CI 0.730.85 ) and an optimism of 0.002 . 
Kidney

Blood Pressure

Research

Fig. 1. Mean predicted mortality risks and observed proportions for ranges of total scores. Prognostic score calculated form the following 5 items well predicts 6-month mortality after maintenance dialysis initiation: age 75 years or older, coronary artery disease, cerebrovascular disease with hemiplegia, time of nephrology care before dialysis, low serum albumin levels.

\begin{tabular}{l|l}
\hline Kidney Blood Press Res 2020;45:38-50 \\
\hline DOI: 10.1159/000504136 & $\begin{array}{l}\text { @ 2019 The Author(s). Published by S. Karger AG, Basel } \\
\text { www.karger.com/kbr }\end{array}$ \\
\hline
\end{tabular}

Santos et al.: Predicting 6-Month Mortality in Incident Elderly Dialysis Patients: A Simple Prognostic Score

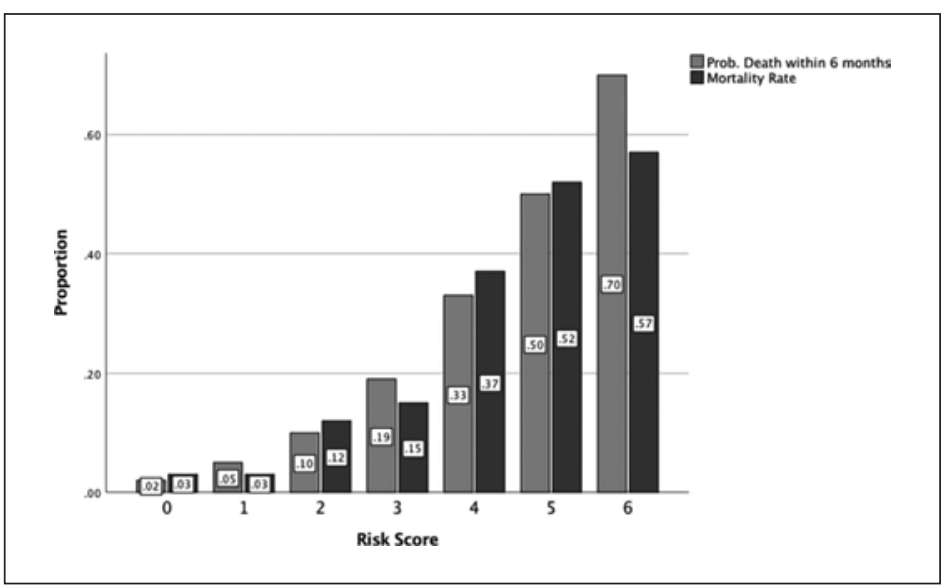

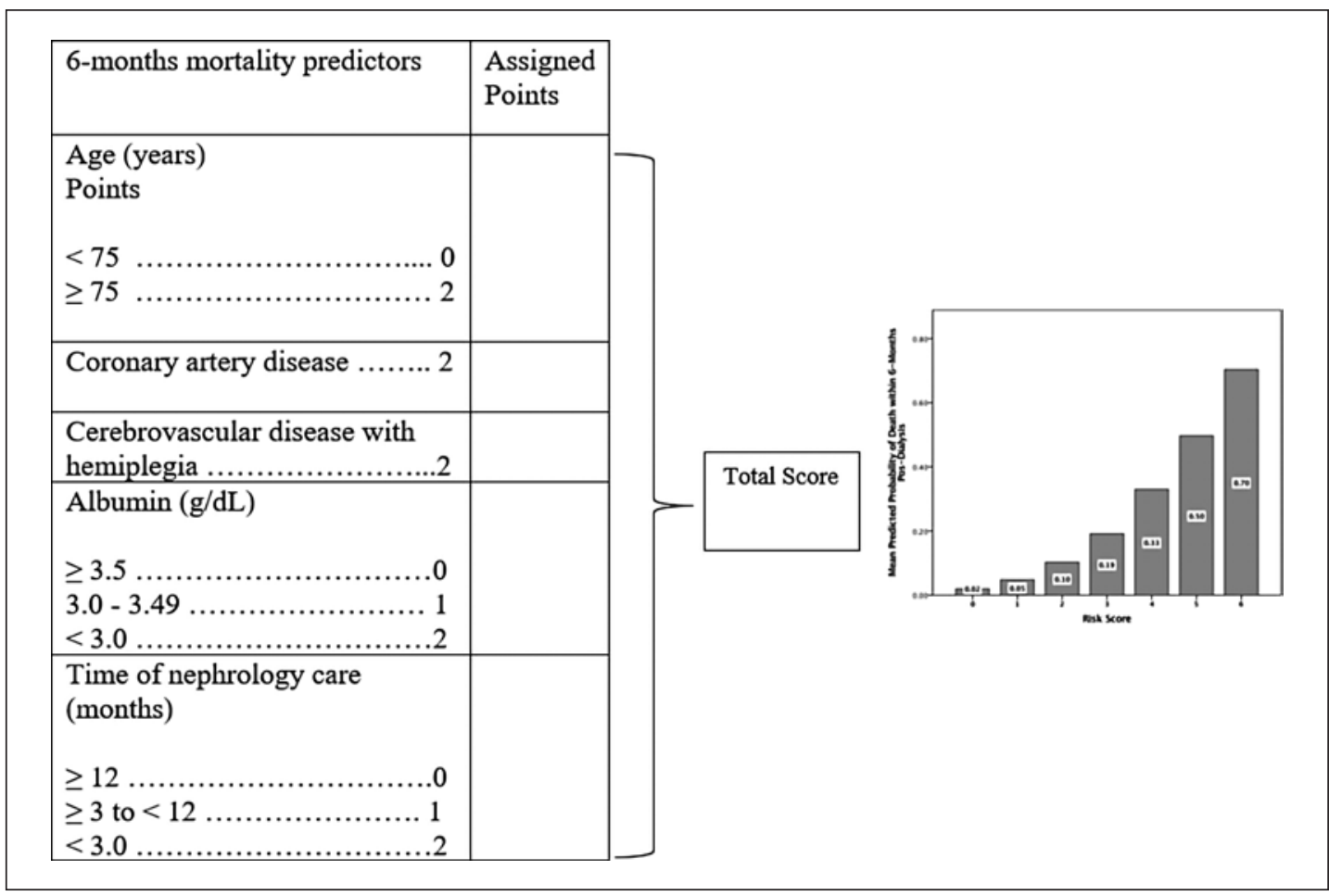

Fig. 2. Score chart to predict 6-month mortality risk after dialysis initiation. Points correspond to each predictor value and are added to give a total score. Points along the X-axis of the plot correspond to approximate probability of mortality within 6 months along the Y-axis.

\section{Comparison with Alternative Risk Scores}

Couchoud score [7] was calculated for all patients in our cohort according to corresponding formula, and the AUC was 0.704 (95\% CI 0.64-0.77). In this cohort, the performance of our score was significantly higher than Couchoud score ( $p=0.026$; Fig. 3$)$. It can be seen that the curve from our score is always above the curve of the Couchoud scale. Therefore, for this particular set of individuals, our score discriminates better between survived and deceased patients. Stated in other way, for a given specificity, our severity score always presents a better sensitivity. 


\section{Kidney \\ Blood Pressure \\ Research}

Fig. 3. Comparison of receiver operating characteristics curves for predicting 6-month mortality after starting dialysis, among our (Santos) and Couchoud scores. ROC, receiver operating characteristics.

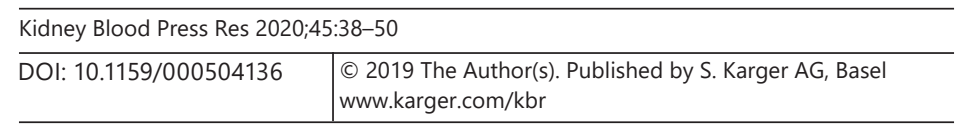

Santos et al.: Predicting 6-Month Mortality in Incident Elderly Dialysis Patients: A Simple Prognostic Score

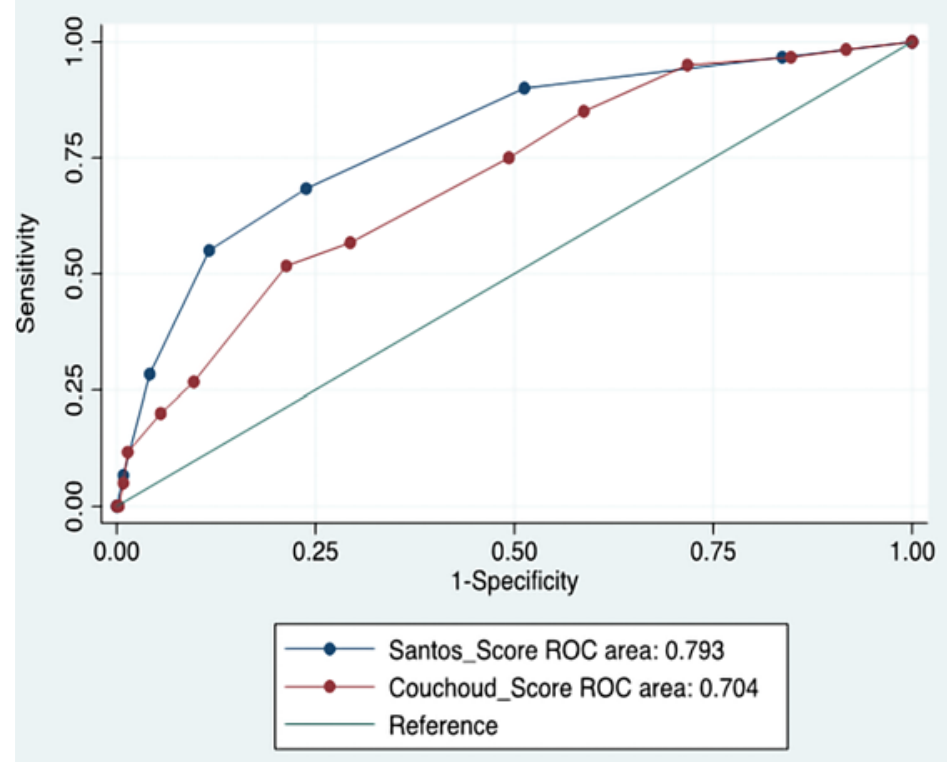

\section{Discussion}

The prognostic score for early mortality developed in this study, defined as death in the 6 months after starting dialysis, is based on simple and ready available information.

Five predictors of 6-month mortality (and their associated scores) were identified: age 75 years or older ( 2 points), coronary artery disease ( 2 points), cerebrovascular disease with hemiplegia ( 2 points), time of nephrology care before dialysis ( $<3.0$ months [ 2 points]; $\geq 3$ to $<12$ months [1 point]), and low serum albumin $(3.0-3.49 \mathrm{~g} / \mathrm{dL}[1$ point] $;<3.0 \mathrm{~g} / \mathrm{dL}$ [2 points]).

In the past years, numerous scores of mortality on dialysis have been developed on the basis of various combinations of comorbidities and laboratory data, but only a few of them focused on short-term survival including only elderly patients [7-10].

Couchoud et al. [7] using just clinical features, based on the French registry data, predicted 6-month mortality in elderly ( $\geq 75$ years) after initiating dialysis. Of the risk factors selected in that model [7], diabetes, peripheral vascular disease, and malignancy were not associated with 6-month mortality in our cohort.

Although diabetes is an important predictor of mortality in CKD patients, in our cohort, diabetes was not associated with early mortality. This agrees with other authors [8-10], and it can be explained by the fact that in our cohort, the burden of other comorbidities in elderly, such as coronary artery disease and cerebrovascular disease, also late complications of diabetes, diminish the significance of diabetes as a predictor of early mortality in ESRD patients.

Congestive heart failure, arrhythmia, and severe behavioral disorder (similar to dementia in our study) were associated with 6-month mortality but were not retained in our final model. This reveals the dissimilarities of the populations used to construct scores.

About $59 \%$ of our patients started with unplanned dialysis, which was not surprisingly associated with high mortality risk, with significantly elevated odds of 6-month mortality, like in Couchoud model [7]. More than half ( $n=140 ; 56 \%)$ of those patients who started with unplanned dialysis were timely referred to nephrologist ( $\geq 12$ months). This can be explained by the fact that this elderly population with high comorbidity has several acute intercurrent illness, which precipitates the need to initiate dialysis. 
Santos et al.: Predicting 6-Month Mortality in Incident Elderly Dialysis Patients: A Simple Prognostic Score

Keeping this in mind, we decided not to include unplanned dialysis in the multivariable analysis, because our final model intended to be a supporting tool even in those patients for whom the dialysis was not scheduled.

More recently, using also the French registry, Couchoud et al. [8] chose to focus on very early mortality (first 3 months of dialysis), in elderly patients. Thamer et al. [10] also focused in early mortality in the first 3 and 6 months using the US Renal Data System proposed a risk score for patients aged $\geq 67$ years. Like these 2 scores $[8,10]$ in our study, age older than 75 and low albumin level were strongly associated with 6-month mortality.

The independent association between hypoalbuminemia and mortality in ESRD was first described in 1990 by Lowrie et al. [20], when a serum albumin $<4 \mathrm{~g} / \mathrm{dL}$ was found to be associated with increased risk for death in dialysis patients. Hypoalbuminemia might indicate malnutrition, but is an important biomarker of acute illness or inflammatory state [21]. Therefore, a multidisciplinary approach, including pre- and post-dialysis management for nutrition, but also dealing with the cause of hypoalbuminemia, might improve survival after initiation of dialysis.

CVD remains the most common cause of mortality in ESRD patients and coronary artery disease is the most frequent cause of cardiovascular death in those patients [22]. The prevalence of CVD in our cohort was very high related to high prevalence of many established risk factors of CVD (diabetes, hypertension, dyslipidemia), also present in our patients.

We have shown that the presence of clinically manifest CVD such as coronary artery disease and cerebrovascular disease with hemiplegia had a significant impact on 6-month mortality within starting dialysis. These 2 variables were not considered or were not predictive in previous models in elderly ESRD patients [7-10]. The presence of cerebrovascular disease with hemiplegia may also reflect the impact of frailty in mortality of CKD patients [23] related to the functional dependency of these patients. These factors provide further evidence of the importance, beyond the usual clinical criteria, of incorporating in the RRT decisions in elderly the assessment of physical and cognitive function, and other components of geriatric syndrome.

Recently, Wick et al. [9] developed a score to estimate mortality risk during the next 6 months for older patient initiating dialysis. They used a large population-based data source in outpatient settings to derive a score in patients 65 years and older, and not only in patients 75 years and older. This is important because as it happens in our cohort, there is an equal number of adults aged 65-74 years who initiate maintenance dialysis therapy as those 75 years and older.

Their final model for 6-month mortality [9] included 7 predictors: age ( $\geq 80$ years), increased eGFR, hospitalization in the prior 6 months, atrial fibrillation, congestive heart failure, metastatic cancer, and lymphoma. None of those variables except older age were strongly predictive in our score, which could be related to differences in the populations from which they were derived. Namely, the incorporation of variables such as lymphoma or metastatic cancer, as mortality predictors, may add clinical utility in contexts in which these conditions appear with reasonable frequency.

In our study, time of nephrology care before dialysis initiation was strongly predictive of early mortality, particularly within 3 months prior to dialysis initiation, but also between 3 and 12 months, compared to >12 months. Several studies have demonstrated that late referral to nephrologist care was a major reason for higher morbidity and mortality on dialysis. This lack of timely evaluation, defined as adequate evaluation to allow for patient and family education, management, and preparation for RRT (e.g., creation of a permanent access) is particularly common in elderly patients [24,25]. Although there is no universally accepted definition of timely referral of patients with CKD, considering a period of 12 months as adequate to provide an acceptable nephrology care [25] was consistent with 


\section{Kidney \\ Blood Pressure \\ Research}

\begin{tabular}{l|l}
\hline Kidney Blood Press Res 2020;45:38-50 \\
\hline DOI: 10.1159/000504136 & $\begin{array}{l}\text { @ 2019 The Author(s). Published by S. Karger AG, Basel } \\
\text { www.karger.com/kbr }\end{array}$ \\
\hline
\end{tabular}

Santos et al.: Predicting 6-Month Mortality in Incident Elderly Dialysis Patients: A Simple Prognostic Score

our results. The appropriate timing of referral is often difficult for nonnephrology physicians. Especially in elderly patients, primary care physicians and nonnephrology specialists were less likely to refer patients to nephrologists than nephrologists were to accept patients for dialysis [26].

Nephrologists should make an effort to support the local network that links primary health-care providers and nephrologists, with improved referral guidelines, and open communication between nephrologists and referring physicians.

With respect to model performance, the proximity of the AUC generated by bootstrapping procedure to the observed AUC and a very acceptable optimism indicate a good discrimination ability of our score. In our population, the performance of our risk score was significantly higher than Couchoud score [7], which reinforces the need to develop predictive scores adapted to the specificities of each population.

To our knowledge, this is the first prognostic score for predicting early death in elderly ESRD patients initiating dialysis that have been developed and internally validated in a Portuguese population. Furthermore, we consider that they are a representative group of the elderly ESRD patients that start dialysis in our country. Differences in our patients' profile, namely, distinct sociodemographic and clinical characteristics compared to other countries, highlight the clinical specificity of our score and the dissimilarities from the other populations used to develop and derive prognostic scores.

Portugal has the highest unadjusted incidence and prevalence of ESRD among European countries [11]. In a recent review [27], elaborated on the factors that potentially underlying observed international differences in CKD prevalence in the elderly, the authors concluded that Portugal had the highest estimate of CKD prevalence, and also the highest average score on CKD risk factors (i.e., diabetes mellitus, raised blood pressure, physical inactivity, and salt intake).

Another important issue is the age pattern at the beginning of RRT. In Portugal, about $62 \%$ of the incident dialysis patients in 2016 were over 65 years with a mean age of 67 years for prevalent patients [28] being one of the oldest in the European registry [11]. In countries with lower RRT incidence, the median age at the start of RRT appears to be lower, suggesting that countries with higher RRT incidence, such as Portugal, start older patients in RRT and this may contribute to differences in RRT epidemiology between countries [29]. In this respect, there is an urgent need for concrete evidence on the relative advantages of conservative treatment versus RRT in the elderly.

There are some limitations of our study. First, this is a single-center retrospective study. Second, our population consisted of incident dialysis patients that were referred to nephrologists. Those who were not referred, not selected for, or not accept to dialysis initiation, were not included. Our model may, therefore, not be generalizable to the entire population of elderly ESRD patients and should not be used to withhold dialysis. Third, despite the internal validation, our model has not been externally validated, which should be a requisite before this tool should be promoted for use in clinical practice. At this moment, our score is being tested in our unit, and it will be applied during the next year with the incident patients and will be subsequently assessed the results.

In conclusion, we have developed and internally validated a predictive risk score for early mortality for elderly CKD patients who initiate dialysis. This simple and accurate prediction score based on readily available data can be an easily implemented tool. Incorporating this prediction model into CKD management for older patients may help to inform patients and their families about ESRD treatment options and provide a more patient-centered overall approach to care. 
Kidney
Blood Pressure
Research

\begin{tabular}{l|l}
\hline Kidney Blood Press Res 2020;45:38-50 \\
\hline DOI: 10.1159/000504136 & $\begin{array}{l}\text { ○ 2019 The Author(s). Published by S. Karger AG, Basel } \\
\text { www.karger.com/kbr }\end{array}$ \\
\hline
\end{tabular}

Santos et al.: Predicting 6-Month Mortality in Incident Elderly Dialysis Patients: A Simple Prognostic Score

\section{Statement of Ethics}

The study was performed in accordance with the Declaration of Helsinki and approved by the Institutional Review Board of CHP. The subjects have given their informed consent.

\section{Disclosure Statement}

The authors have no conflicts of interest to declare.

\section{Author Contributions}

The authors contributed to this article in the following way: J.S. and I.F.: study design; J.S., A.C., and S.O.: data collect; J.S., P.O, and I.F.: data analysis; J.S., P.O., A.C., L.L., and I.F.: methodology; J.S. and I.F: manuscript preparation.

\section{References}

1 Pippias M, Jager KJ, Kramer A, Leivestad T, Sánchez MB, Caskey FJ, et al. The changing trends and outcomes in renal replacement therapy: data from the ERA-EDTA Registry. Nephrol Dial Transplant. 2016 May;31(5): 831-41.

2 Murtagh FE, Marsh JE, Donohoe P, Ekbal NJ, Sheerin NS, Harris FE. Dialysis or not? A comparative survival study of patients over 75 years with chronic kidney disease stage 5. Nephrol Dial Transplant. 2007 Jul;22(7): 1955-62.

3 Kurella Tamura M, Covinsky KE, Chertow GM, Yaffe K, Landefeld CS, McCulloch CE. Functional status of elderly adults before and after initiation of dialysis. N Engl J Med. 2009 Oct;361(16):1539-47.

4 Carson RC, Juszczak M, Davenport A, Burns A. Is maximum conservative management an equivalent treatment option to dialysis for elderly patients with significant comorbid disease? Clin J Am Soc Nephrol. 2009 Oct; 4(10):1611-9.

5 Cohen LM, Ruthazer R, Moss AH, Germain MJ. Predicting six-month mortality for patients who are on maintenance hemodialysis. Clin J Am Soc Nephrol. 2010 Jan;5(1):72-9.

6 Chua HR, Lau T, Luo N, Ma V, Teo BW, Haroon S, et al. Predicting first-year mortality in incident dialysis patients with end-stage renal disease - the UREA5 study. Blood Purif. 2014;37(2):85-92.

7 Couchoud C, Labeeuw M, Moranne O, Allot V, Esnault V, Frimat L, et al.; French Renal Epidemiology and Information Network (REIN) registry. A clinical score to predict 6-month prognosis in elderly patients starting dialysis for end-stage renal disease. Nephrol Dial Transplant. 2009 May;24(5):1553-61.

8 Couchoud CG, Beuscart JB, Aldigier JC, Brunet PJ, Moranne OP; REIN registry. Development of a risk stratification algorithm to improve patient-centered care and decision making for incident elderly patients with endstage renal disease. Kidney Int. 2015 Nov;88(5):1178-86.

9 Wick JP, Turin TC, Faris PD, MacRae JM, Weaver RG, Tonelli M, et al. A Clinical Risk Prediction Tool for 6-Month Mortality After Dialysis Initiation Among Older Adults. Am J Kidney Dis. 2017 May;69(5):568-75.

10 Thamer M, Kaufman JS, Zhang Y, Zhang Q, Cotter DJ, Bang H. Predicting Early Death Among Elderly Dialysis Patients: Development and Validation of a Risk Score to Assist Shared Decision Making for Dialysis Initiation. Am J Kidney Dis. 2015 Dec;66(6):1024-32.

11 Pippias M, Kramer A, Noordzij M, Afentakis N, Alonso de la Torre R, Ambühl PM, et al. The European Renal Association - European Dialysis and Transplant Association Registry Annual Report 2014: a summary. Clin Kidney J. 2017 Apr;10(2):154-69.

12 Levey AS, Stevens LA, Schmid CH, Zhang YL, Castro AF 3rd, Feldman HI, et al.; CKD-EPI (Chronic Kidney Disease Epidemiology Collaboration). A new equation to estimate glomerular filtration rate. Ann Intern Med. 2009 May;150(9):604-12.

13 Folstein MF, Folstein SE, McHugh PR. "Mini-mental state". A practical method for grading the cognitive state of patients for the clinician. J Psychiatr Res. 1975 Nov;12(3):189-98.

14 Charlson ME, Pompei P, Ales KL, MacKenzie CR. A new method of classifying prognostic comorbidity in longitudinal studies: development and validation. J Chronic Dis. 1987;40(5):373-83.

15 Royston P, Sauerbrei W. Multivariable Model-Building - A Pragmatic Approach to Regression Analysis based on Fractional Polynomials for Modelling Continuous Variables. Chichester: John Wiley \& Sons Ltd; 2008.

16 Royston P, Moons KG, Altman DG, Vergouwe Y. Prognosis and prognostic research: developing a prognostic model. BMJ. 2009 Mar;338:b604. 
17 Moons KG, Donders AR, Steyerberg EW, Harrell FE. Penalized maximum likelihood estimation to directly adjust diagnostic and prognostic prediction models for overoptimism: a clinical example. J Clin Epidemiol. 2004 Dec;57(12):1262-70.

18 Harrell FE Jr, Lee KL, Mark DB. Multivariable prognostic models: issues in developing models, evaluating assumptions and adequacy, and measuring and reducing errors. Stat Med. 1996 Feb;15(4):361-87.

19 Doi T, Yamamoto S, Morinaga T, Sada KE, Kurita N, Onishi Y. Risk Score to Predict 1-Year Mortality after Haemodialysis Initiation in Patients with Stage 5 Chronic Kidney Disease under Predialysis Nephrology Care. PLoS One. 2015 Jun;10(6):e0129180.

20 Lowrie EG, Lew NL. Death risk in hemodialysis patients: the predictive value of commonly measured variables and an evaluation of death rate differences between facilities. Am J Kidney Dis. 1990 May;15(5):458-82.

21 Don BR, Kaysen G. Serum albumin: relationship to inflammation and nutrition. Semin Dial. 2004 Nov-Dec; 17(6):432-7.

22 Thompson S, James M, Wiebe N, Hemmelgarn B, Manns B, Klarenbach S, et al.; Alberta Kidney Disease Network. Cause of death in patients with reduced kidney function. J Am Soc Nephrol. 2015 Oct;26(10):2504-11.

23 Shlipak MG, Stehman-Breen C, Fried LF, Song X, Siscovick D, Fried LP, et al. The presence of frailty in elderly persons with chronic renal insufficiency. Am J Kidney Dis. 2004 May;43(5):861-7.

24 Schwenger V, Morath C, Hofmann A, Hoffmann O, Zeier M, Ritz E. Late referral-a major cause of poor outcome in the very elderly dialysis patient. Nephrol Dial Transplant. 2006 Apr;21(4):962-7.

25 de Jager DJ, Voormolen N, Krediet RT, Dekker FW, Boeschoten EW, Grootendorst DC; NECOSAD Study Group. Association between time of referral and survival in the first year of dialysis in diabetics and the elderly. Nephrol Dial Transplant. 2011 Feb;26(2):652-8.

26 Visser A, Dijkstra GJ, Huisman RM, Gansevoort RT, de Jong PE, Reijneveld SA. Differences between physicians in the likelihood of referral and acceptance of elderly patients for dialysis-influence of age and comorbidity. Nephrol Dial Transplant. 2007 Nov;22(11):3255-61.

27 Stel VS, Brück K, Fraser S, Zoccali C, Massy ZA, Jager KJ. International differences in chronic kidney disease prevalence: a key public health and epidemiologic research issue. Nephrol Dial Transplant. 2017 Apr 1; 32(suppl_2):ii129-35.

28 Substitutive Renal Therapy of Chronic Renal Disease in Portugal. [Accessed Jun 30, 2017]. Available from: http:www.spnefro.pt/comissoes_Gabinete_registo_2016/registo_2016.

29 Gonzalez-Espinoza L, Ortiz A. 2012 ERA-EDTA Registry Annual Report: cautious optimism on outcomes, concern about persistent inequalities and data black-outs. Clin Kidney J. 2015 Jun;8(3):243-7. 